\title{
Public Awareness and Perception of Renewable Energy and Systems and Related Educational Needs in Turkey and Bulgaria
}

\author{
Mehmet SEN \\ Bursa Uludağ University, Bursa, Turkey, mehmetsen@uludag.edu.tr \\ Ridvan ARSLAN \\ Bursa Uludağ University, Bursa, Turkey, ridvan@uludag.edu.tr \\ Yahya ULUSOY \\ Bursa Uludağ University, Bursa, Turkey, yahyau@uludag.edu.tr \\ Pancho TOMOV \\ Technical University, Sofia, Bulgaria, pkt@tu-sofia.bg
}

\begin{abstract}
This study analysed the awareness and perception of individuals in Bulgaria and Turkey on the topic of renewable energy (RE) and the need for education about it. The study was carried out in order to provide an infrastructure for developing training modules at each educational level. A survey of public perception, awareness and lack of information was given to a total of 453 participants from Turkey and Bulgaria and the results were evaluated using the difference analysis method and SPSS software. Evaluation of the results obtained from Bulgaria and Turkey showed similar findings in terms of the general trend for the various topics. In both countries there was an awareness of RE that cannot be underestimated. However, along with this, the RE awareness and perception decreased as the subject turned from theoretical concepts to technical details. In other words, the technical knowledge was insufficient to support the perception and awareness that existed at the level of the general culture. The results of the study revealed that educational planners and concerned parties should give more emphasis in their studies to awareness and perception of the topic to be established through educational institutions and via the media.
\end{abstract}

Keywords

perception, awareness, renewable energy, educational needs

\section{Introduction}

Renewable energy (RE) sources such as solar, wind and biomass, nuclear power and hydrogen fuel cells are attracting more attention than non-renewable sources of energy as they are environmentally friendly and produce less air pollution. Serious renewable energy potential officially exists in Turkey and has been established through scientific research. There is also widespread work on the availability of RE sources, especially biofuels [1-4]. However, RE usage still faces obstacles in the form of regulations, the marketplace, geographic location and the specific technology used and from the local people. Understanding public attitudes and perceptions of the environmental impact and preferences in technologies and systems for mitigating greenhouse gas emissions is important for decision makers as a way of developing proper communication strategies with the public [5]. In addition to decision makers, suppliers need to offer RE resources that will satisfy environmentally conscious consumers. These firms wish to know how to educate consumers in order to encourage the use of renewable power that is substantially beneficial in terms of reducing environmental harm and ensuring safe energy production [6]. Investigating the knowledge and perceptions, as well as attitudes of the public concerning various aspects of RE usage is also of great importance to environmental education [7]. There are numerous studies investigating perceptions of RE concepts both theoretical and in case studies. In their study conducted in south-western UK, West et al. [8] examined the cultural theory framework and focus groups to develop deeper understandings of how individual worldviews can shape opinions and behaviour in relation to RE. Their findings were used to explore ways in which government policies on RE might be tailored to engender greater public support and participation. Using a survey-based 
analysis, Eshchanov et al. [9] investigated decision-makers' perceptions of the introduction of RE sources in the residential sector of Uzbekistan. Their findings indicated that the possibility of becoming independent from the centrally supplied natural gas and electricity grid and the availability of statefunded financing were the three main motivators of RE implementation, while the higher price of energy from RE sources acted as a major disincentive. As an alternative to traditional resources, the use of RE resources is increasing rapidly all over the world.

There has also been research carried out in Turkey to explore the level of awareness regarding RE among Turkish university students. Studies in various disciplines on RE sources need to be conducted in many universities in order to increase the awareness level of university students about RE sources [10]. Irmak et al. [11], in their survey to determine the RE awareness of students in Ankara, determined that there was an increasing awareness among university students as expected. In addition, their study revealed a more reliable perception of RE in society. A case study in India showed that $80 \%$ of rural respondents had not heard of RE subsidies, while $61 \%$ of commercial/industrial respondents were unaware of government subsidies for RE and $54 \%$ of residential respondents were also not aware of such subsidies [12]. There are also some notable studies on the awareness and perception of end users or investors on different renewable energy sources such as smart grid, solar, biogas, etc. [13-15].

This paper aimed to address public perceptions and awareness of RE concepts and related educational needs in Turkey and Bulgaria via a questionnaire in order to develop new educational modules as a lifelong learning framework.

\section{Methodology}

First, a study related to the topic was carried out with the target audience in order to establish a reliable base for awareness and analyse their needs. During this study, answers were sought to questions such as: "Who are the directors of the RE educational activities and who are the practitioners in the field?" "Who are the beneficiaries of the education?" "Who are envisaged as reaching the level of RE awareness in terms of the social environment?" As a result of this stakeholder analysis, students were identified as the main and internal stakeholders, while external stakeholders included universities, secondary educational institutions, relevant sector representatives and their employees and nongovernmental organizations.

\subsection{Needs analysis}

The main objective of the needs analysis was to identify the stakeholders' perception and awareness and to measure the difference between the current status of the level of knowledge and the required or desired status. In this study, first, a survey scale development study was carried out on the subject. In the evaluation of the scale developed based on the questionnaire, the difference approach method was used to reveal the difference between observed and expected levels. When the scale was being prepared, as will be seen in the following section, care was taken that the questions did not contain any definite specifications or leading statements and that the input sentences which began with "I think ..." should be completed.

In the questionnaire survey, the ten questions of the awareness and perception question groups were prepared on a 5-point Likert scale. There were also five open-ended questions on the survey for determining the need for education. The survey was directed to all parties identified as the target audience / stakeholders involved in the survey via the Google survey application. These question groups enabled us to make a very different evaluation during the analysis and made it possible to investigate the findings. The question groups were primarily concerned with the differences between the countries, the relationship between educational status and perception-awareness, the sufficiency of education levels, etc.

\subsection{Statistical analysis}

All statistical analyses were performed with the SPSS program. The survey method was used in order to carry out user evaluation. The survey was based on the country and the occupational and educational parameters of 453 participants living in Turkey and Bulgaria. In the study, 374 people from Turkey and 
79 from Bulgaria participated. Of the participants in both countries, 86.5\% were high-school graduates and $13.5 \%$ had finished middle school.

\section{Research Findings \& Evaluation}

\subsection{Awareness results}

In Fig. 1, averages of the responses to the awareness questions are given for both countries. The chart shows the results of the general evaluation of the of participants' awareness behaviour concerning RE. The results obtained from Turkey and Bulgaria were similar in terms of general trends, but varied according to the topic.

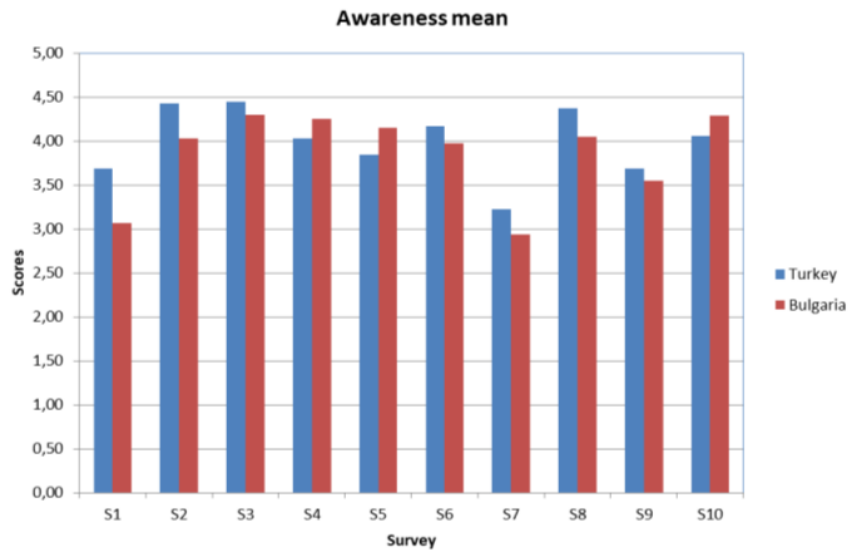

Fig. 1. General averages based on awareness questions

Since the data collected in the statistical study did not show a normal distribution, in order to test whether there were significant differences between Turkey and Bulgaria on awareness, the MannWhitney U comparison test was performed. As seen in Table 1, no significant difference was observed between the profiles of Turkey and Bulgaria on awareness ( $p=0.01<0.05)$.

Table 1. Differences in awareness

\begin{tabular}{cccccc}
\hline Group & N & Rank Average & Rank Total & $\mathbf{U}$ & $\mathbf{p}$ \\
\hline Turkey & 374 & 234.26 & 87613 & 12058 & 0.01 \\
\hline Bulgaria & 79 & 192.63 & 15218 & & \\
\hline
\end{tabular}

For the fourth question ("You have enough knowledge about the concepts of global warming and greenhouse gas emissions") and the fifth question ("You have enough knowledge about carbon emissions") the percentage of positive answers in Turkey was 79\%, while it was $84 \%$ in Bulgaria. The proportional decrease on behalf of Turkey for these last two questions is remarkable. Thus, while the participants had a higher awareness of the general concept of RE, there was a reduction in awareness of more specific issues such as clean energy and the greenhouse effect. In Bulgaria, no reduction in awareness was observed.

For the sixth question ("You know the source of fossil fuels in the area where you live and the environmental impact of fossil fuels") the percentage of positive responses for Turkey was $83 \%$ and for Bulgaria 80\%. For the seventh question ("You know about the Kyoto Protocol and other international clean energy criteria") the percentage of positive responses for Turkey was $64 \%$ and for Bulgaria only $59 \%$. This most striking and dramatic decline showed that participants in neither country seemed to have sufficient knowledge of the Kyoto protocol and other international clean energy criteria. This was in fact an expected outcome, and while the RE awareness was generally high, it turned out that there were serious deficiencies in awareness when it came down to details. For the eighth question ("You think rural and urban organic wastes can be converted into RE") the percentage of positive responses for Turkey was $87 \%$ and for Bulgaria $81 \%$. For the ninth question ("You know that RE is supported by the State") the percentage of positive responses for Turkey was $74 \%$ and for Bulgaria $71 \%$. For the tenth 
question ("You have enough information about energy efficiency") the percentage of positive responses for Turkey was $81 \%$ and for Bulgaria $86 \%$.

The overall average for the awareness questions for Turkey was $80 \%$ and for Bulgaria $77 \%$. This clearly demonstrated the need for awareness-raising activities in the subject areas where the results were measured in close proximity to one another and were felt to be insufficient.

\subsection{Perception results}

Since the collected data were not normally distributed in the evaluation of the perception results, and in order to test whether there was a significant difference between the perceptions, the MannWhitney U comparison test was performed. As shown in Table 2, a significant difference between the perceptions of Turkey and Bulgaria was observed in the test results $(p=0.00<0.05)$.

Table 2. Differences in perception

\begin{tabular}{cccccc}
\hline Group & $\mathbf{N}$ & Rank Average & Rank Total & $\mathbf{U}$ & $\mathbf{p}$ \\
\hline Turkey & 374 & 238.87 & 87613 & 10333 & 0.00 \\
\hline Bulgaria & 79 & 170.80 & 15218 & & \\
\hline
\end{tabular}

In Fig. 2 the averages of the responses to the perception questions are given for both countries. The first perception group question was the eleventh question ("You are trying to take the necessary precautions concerning energy efficiency") the percentage of positive responses for Turkey was 78\% and for Bulgaria 77\%. These ratios indicated that perception of this topic was high in both countries. With the twelfth and thirteenth questions ("You find the state support given to RE to be sufficient and satisfactory" and" You think there is a need to comply unconditionally with international regulations for clean energy") the average percentage of positive responses for Turkey was $89 \%$ and for Bulgaria $78 \%$. The reason for the difference seen here in favor of Turkey can be attributed to the government support given to RE investments in recent years, especially for wind and solar energy.

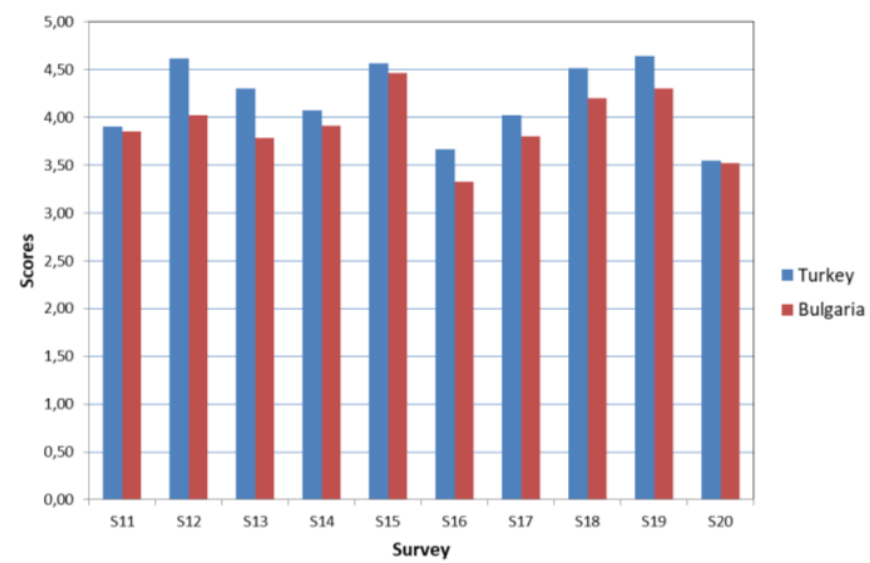

Fig. 2. General averages for perception questions

For the fourteenth question ("Would you consider buying electricity from a renewable source even if it were a bit expensive?") and for the seventeenth question ("If you had a chance to choose, would you prefer renewable energy, even if it were more expensive?") the percentage of positive responses for Turkey and Bulgaria were $81 \%$ and $77 \%$, respectively. These two answers show that the perception of the use of RE for both countries was high and positive.

The other three questions that can be grouped by answers are the fifteenth question ("You support the use of renewable energy in public transport") with the eighteenth and nineteenth questions ("You support the installation of renewable energy facilities in your region." and "You support the establishment of a solar panel on the roof of the site or houses you live in."). The mean percentages of positive responses to these three questions for Turkey and Bulgaria were $91 \%$ and $86 \%$, respectively. Again, this suggested a high positive perception of the installation of RE systems. 
For the sixteenth question ("You are questioning whether you use renewable energy or not") the percentage of positive responses for Turkey and Bulgaria were $73 \%$ and $67 \%$, respectively. The positive responses for the 20th and final perception criterion ("You think clean and renewable energy concepts are not the same") were $71 \%$ for both countries. The proportion of these responses in the low percentage meant that the existing level of RE consciousness was not a priority in practical life; in other words, the rate of questioning was low. It is important to emphasize perception activities in order to close this gap.

\subsection{Educational needs analysis}

The following considerations were made when analysing the questions that were asked in the study under the topic of training. For example, "Have you received any lessons on RE during your education?" The rate of "Yes" answers to the question for Turkey was 61\%, and for Bulgaria $72 \%$.That meant that more than half of the respondents had been taught about RE. For the question "At what stage of your education were you taught about RE?", as given in Fig. 3, for 78\% in Turkey it came up during university, whereas for $51 \%$ in Bulgaria it was covered during secondary school. These responses also meant that the RE topics differed from country to country, but were weighted within the content of secondary education and university education.

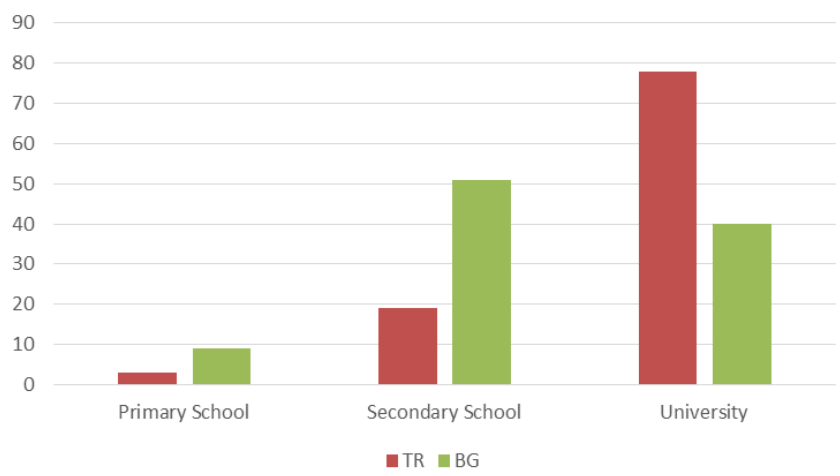

Fig. 3. Educational levels during which RE lessons were taught

To the question "Have you been taught about RE outside of your educational life?" 13\% in Turkey and $12 \%$ in Bulgaria gave the answer "Yes". This meant that other than during the course of normal education, RE subjects were not being taught in certificate training programs or in-house training, which is a serious deficit.

The answer to the question which can be the most important question in this group ("At what stage of your education should RE lessons be given?") is seen in Fig. 4, which shows the general opinion to be that RE should be taught at the secondary educational level, although there was a division in the percentage results between the two countries. Again, for Turkey, the primary education option was dominant. In other words, the participants clearly expressed their opinion that RE education should be started from primary school and should be given at every level according to the need.

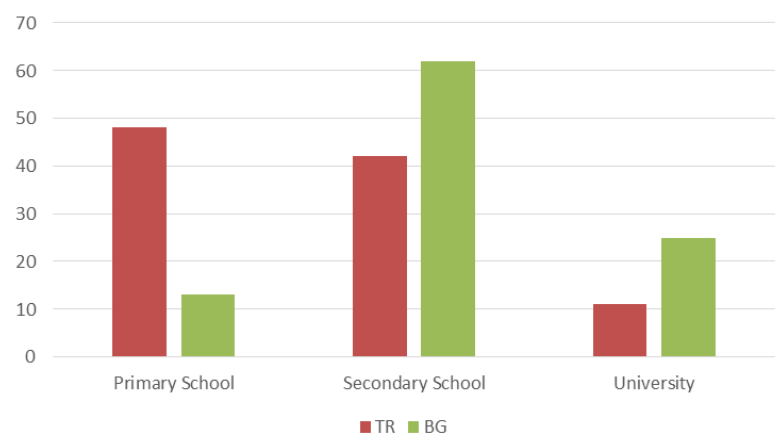

Fig. 4. Educational levels at which RE courses should be introduced in future 


\section{Conclusion and Recommendations}

This study was able to conduct a number of wide-ranging analyses which constitute an important database in terms of both the number and the diversity of participants. Many sub-analyses not given in the above findings were also carried out according to educational status, country and occupation. In summary, the following conclusions can be drawn from this study, conducted mainly via detailed analyses based on survey questions.

There was an awareness of RE in both countries that cannot be underestimated, and this situation is positive. However, the awareness and perception of theoretical RE concepts decreased when it came to technical details. In other words, the perception of awareness that existed at the level of general culture could not be supported with sufficient technical knowledge. This finding was also reinforced by the educational needs questions. The general opinion was that in future, RE education should begin from primary school and be offered at every level according to the need, although there was a difference in the percentage results between the two countries.

As a result of this study, it can be said that the educational planners and concerned parties have emphasized that RE awareness and perception studies should be established from the primary education level and promulgated via educational institutions and the media. In this context, it is important to support these issues which will increase the awareness of RE related with course contents at primary and secondary education level and support with applications to use visual tools such as virtual reality or animation. At university level, Increasing the number of elective courses in the RE field and raising awareness through short-term certification programs are so important. It is a clear fact that the most important work to increase both the social perception and awareness of RE concepts will be the spotlight tools which will be prepared by the media tools and program developers.

\section{References}

1. Arslan R. (2007): Agricultural and Economic Potential of Biodiesel in Turkey. Energy Sources, Part B, eISSN 15567257, Vol. 2, is. 3, pp. 305-310, https://doi.org/10.1080/15567240600629476

2. Arslan R., Ulusoy Y., Sürmen A. (2006): Türkiyede Biyodizel Potansiyeli (Biodiesel Potential in Turkey). Automotive Technologies Congress, OTEKON06, Bursa, Turkey (in Turkish)

3. Arslan R., Tekin Y., Ulusoy Y., Sürmen A. (2010): An Evaluation of Alternative Transport Fuels for Turkey. Energy Policy, ISSN0301-4215, Vol. 38. Is. 6, https://doi.org/10.1016/J.ENPOL.2010.01.042

4. Ulusoy Y., Arslan R., Tekin Y., Sürmen A. (2008): An Evaluation on Bio-Diesel Policies in Turkey. International Conference on Automotive Technology - ICAT 2008, Istanbul, Turkey

5. Abdmouleh Z., Gastli A., Ben-Brahim L. (2008): Survey about public perception regarding smart grid, energy efficiency \& renewable energies applications in Qatar. Renewable and Sustainable Energy Reviews, ISSN 13640321, Vol. 82, Part 1, pp. 168-175, https://doi.org/10.1016/i.rser.2017.09.023

6. Ocetkiewicz I., Tomaszewska B., Mróz A. (2007): Renewable energy in education for sustainable development: The Polish experience. Renewable and Sustainable Energy Reviews, ISSN 1364-0321, Vol. 80, pp. 92-97, https://doi.org/10.1016/i.rser.2017.05.144

7. Lin C.-Y., Syrgabayeva D. (2016): Mechanism of environmental concern on intention to pay more for renewable energy: Application to a developing country. Asia Pacific Management Review, ISSN 1029-3132, Vol. 21, is. 3, pp. 125-134, https://doi.org/10.1016/i.apmrv.2016.01.001

8. West J., Bailey I., Winter M. (2010): Renewable energy policy and public perceptions of renewable energy: $A$ cultural theory approach. Energy Policy, ISSN 0301-4215, Vol. 38, is. 10, pp. 5739-5748, https://doi.org/10.1016/j.enpol.2010.05.024

9. Eshchanov B.R., Grinwis Plaat Stultjes M., Eshchanov R.A., Salaev S.K. (2013): Prospects of renewable energy penetration in Uzbekistan - Perception of the Khorezmian people. Renewable and Sustainable Energy Reviews, ISSN1364-0321, Vol. 21, pp. 789-797, https://doi.org/10.1016/j.rser.2013.01.023

10. Karatepe Y., Neşe S.V., Keçebaş A., Yumurtacı M. (2012): The levels of awareness about the renewable energy sources of university students in Turkey. Renewable energy, ISSN 0960-1481, Vol. 44, pp. 174-179, https://doi.org/10.1016/j.renene.2012.01.099

11. Irmak E., Ayaz M.S., Gok S.G., Sahin A.B. (2014): A survey on public awareness towards renewable energy in Turkey. In: 2014 International Conference on Renewable Energy Research and Application (ICRERA), eISBN 978-1-4799-3795-0, pp. 932-937, DOI: 10.1109/ICRERA.2014.7016523

12. Mercom Capital Group (2011): India renewable energy awareness survey. India

13. Buluc, B., Bulbul, H.I. (2016): Increasing Social Awareness of Consumer Behaviors on Smart Grids Energy Systems. 
International Journal of Renewable Energy Research (IJRER), eISSN 1309-0127, Vol 6, no. 4, pp. 1588-1592, https://www.ijrer.com/index.php/ijrer/article/view/5154/pdf

14. Sarin A., Gupta R., Jituri V.V. (2018): Solar Residential Rooftop Systems (SRRS) in South Delhi: A Strategic Study with Focus on Potential Consumers' Awareness. International Journal of Renewable Energy Research (IJRER), eISSN 1309-0127, Vol. 8, no 2, pp. 954-963, https://www.ijrer.org/ijrer/index.php/ijrer/article/view/ $\underline{7603 / \mathrm{pdf}}$

15. Islam A.R., Hossein M.S. (2014): Livestock Farmers' Knowledge, Perceptions, and Attitudes toward Biogas Plant in Bangladesh. International Journal of Renewable Energy Research (IJRER), eISSN 1309-0127, Vol. 4, no 1, pp. 77-82, https://www.ijrer.org/ijrer/index.php/ijrer/article/view/1013/pdf 